\title{
REFLEXO E REINVENÇÃO DA REALIDADE: QUANDO O CINEMA ENCONTRA A GUERRA
}

\author{
REFLEX AND REINVENTION OF REALITY: WHEN THE MOVIE INDUSTRY \\ MEETS WAR
}

\author{
REFLEXIÓN Y RECONVERSIÓN REALIDAD: CUANDO EL CINE ES \\ GUERRA
}

\author{
Denise Marcos Bussoletti \\ Professora do Programa de Pós- \\ Graduação da Universidade \\ Federal de Peloras (FaE/UFPel) \\ denisebussoletti@gmail.com \\ Joice do Prado Alves \\ Mestre em Educação pela \\ Universidade Federal de Pelotas \\ (FaE/UFPel) \\ joiceprado@yahoo.com.br
}

\section{Resumo}

Esse artigo busca traçar considerações sobre o papel da imagem cinematográfica no mundo contemporâneo, suas implicações, influências e funções propagandísticas, elencando enquanto recorte histórico-temporal o contexto da Guerra Fria. Através das discussões com Walter Benjamin, Marcel Martin, Graeme Turner e Marc Ferro, pretendemos mostrar que o cinema não é neutro, especificamente o cinema norte-americano, que foi plenamente capaz de gerar noções de pertencimento à nação e criar o estereótipo do inimigo comum nesse período turbulento onde duas ideologias entravam em conflito.

Palavras-chave: Cinema. Guerra Fria. Propaganda.

\begin{abstract}
This article intend to make considerations about the cinematic image in the contemporary world, its implications, influences and propaganda functions, in the context of the Cold War. Discussing with Walter Benjamin, Marcel Martin, Graeme Turner and Marc Ferro, we intend to show that cinema is not neutral, specifically American cinema, which was fully capable of generating notions of belonging to the nation and create the stereotype of the common enemy in this turbulent period where two ideologies clashed.
\end{abstract}

Keywords: Cinema. Cold War. Propaganda. 


\section{Resumen}

En este artículo se explica el papel de la imagen de la película en el mundo contemporáneo, sus implicaciones, influencias y funciones de propaganda, enumerando como marco de tiempo el contexto histórico de la Guerra Fría. Através de conversaciones con Walter Benjamin, Marcel Martin, Graeme Turner y Marc Ferro, tenemos la intención de demostrar que el cine no es neutral, específicamente la industria del cine estadounidense, totalmente capaz de crear el estereotipo del enemigo común en uno período turbulento en el que dos ideologías se enfrentaron.

Palabras clave: Cinema. Guerra Fría. Propaganda.

\section{INTRODUÇÃO}

Imagens. É basicamente o que enxergamos quando olhamos o mundo que nos rodeia. Da televisão às revistas, passando pelo cinema e pelas propagandas nas ruas, estamos cercados pelas cores, pelas formas e pelos slogans que nos atingem de forma mais ou menos sutil, adentrando nosso inconsciente de maneira quase imperceptível.

Essa relação não é nova, datando dos primórdios da humanidade, quando ainda nos comunicávamos por desenhos em paredes de cavernas. Desde então, esse relacionamento se estreitou, evoluindo ao ponto de se tornar uma elaborada ferramenta propagadora de ideias, discursos, estilos de vida e visões de mundo.

Se a arte em sua forma mais tradicional nos aproximou da representação da realidade através da imagem, os movimentos artísticos que começaram a vigorar a partir do século XX, juntamente com a fotografia e o cinema, sem dúvida nos trouxeram a subversão dessa representação, rompendo a barreira da mimese e inaugurando uma nova forma de diálogo. $\mathrm{O}$ mundo imagético passava a refletir sobre a realidade social, cultural e econômica, mostrando em suas formas o pensamento dos indivíduos sobre o mundo que os cercava. Rompia assim os muros da imitação e adentrava o caminho da criatividade.

Esse caminho nunca foi fácil, muito menos neutro. A medida que a imagem conquistou seu espaço no cotidiano, sua força aumentou. Sem dúvida nenhuma o cinema teve papel fundamental nesse acúmulo de poder, posto que a partir do funcionamento real do cinematógrafo ${ }^{1}$ pelos irmãos Lumière na Paris do século XIX (ALVES; ALVES; 2012), uma nova linguagem se desenvolvia: a linguagem cinematográfica da imagem.

\footnotetext{
1 Aparelho de projeção desenvolvido pelos irmãos Lumière que projetaram o primeiro filme sequencial da história.
} 
Buscaremos aqui traçar algumas considerações sobre a relação do cinema e da imagem enquanto possuidoras de uma forte capacidade de diálogo e também de discurso a partir do contexto da Guerra Fria. Note-se que esses dois conceitos (diálogo e discurso) são e devem ser bem diferenciados. Enquanto a capacidade dialógica da imagem remete à construção de um pensamento crítico e ao desenvolvimento da sensibilidade do olhar, a capacidade discursiva da imagem nos traz justamente à imposição de uma ideia que vigora por traz da máscara do entretenimento, do drama ou do emotivo.

A Guerra Fria é eleita enquanto palco das discussões por se tratar de um período histórico delicadamente conturbado, onde, na mentalidade das pessoas comuns, cada dia poderia ser o último dada a recente demonstração da força norte-americana em Hiroshima e Nagasaki; e onde, além disso, duas ideologias entravam em um enorme conflito psicológico.

A imagem, durante os cerca de cinquenta anos que marcam o conflito, se tornou uma arma letal e poderosa usada por ambos os lados. Longe de atacar fisicamente seus adversários, os países atacaram o inconsciente coletivo, estereotipando seus inimigos e criando um conceito heroico entorno de si mesmos (MASCARELLO, 2001).

Por ser um extenso caminho a ser percorrido, elencaremos para essa discussão apenas os filmes feitos pelos norte-americanos. Hollywood se consolidou como uma das maiores forças do governo americano, transformando um sentimento de superioridade que já advinha de sua independência em imagem, algo observável e consumível. Sem dúvida nenhuma, se os alemães nazistas ajudaram a alavancar o cinema enquanto uma enorme ferramenta aliada à propagação de discursos, a Guerra Fria assim o consolidou.

\section{A PARCIALIDADE CINEMATOGRÁFICA}

O cinema não é neutro e nem a imagem o é. Mesmo nas representações artísticas mais antigas e tradicionais, o olhar do artista sempre criou uma barreira entre o que é visto e o que é retratado, barreira intransponível, pessoal e subjetiva. O cinema, também feito por uma equipe e filtrado pelos olhos do diretor, jamais poderá retratar fielmente a realidade como ela é, justamente por passar por esse olhar que é diferente para cada um.

Marie-Thérèse Journout (2005), já afirmou que a neutralidade do cinema não é possível principalmente pelo fato de ele ser feito por alguém e para alguém. Permeando esse fato, o cinema carrega consigo duas características que ajudam a torná-lo extremamente parcial, fazendo dele aquilo que ele é: linguagem e discurso. 
Caminha, portanto, sobre uma tortuosa trilha que ora o condena - ao ser considerado propagador de discursos e assim ser taxado de meio de comunicação de massa - e ora o redime, ao ser elevado à categoria de arte graças a sua linguagem, perfeitamente capaz de traçar diálogos que levam o expectador a pensar sobre o mundo ao seu redor (MARTIN, 2007).

Dificilmente conseguiremos exemplos de um cinema que seja pura arte ou de outro que seja puramente propagandístico. $\mathrm{Na}$ medida que os filmes foram se desenvolvendo em sua cota tecnológica, os jogos de câmera, luz e som conferiram o caráter artístico ao cinema, ainda que determinado filme seja desenvolvido exclusivamente para fins discursivos. Exemplo disso são os filmes de Leni Riefenstahl, cineasta favorita de Hitler e responsável pelos maiores documentários do regime nazista. A "mulher nazista ideal" do Führer desenvolveu com tanto esmero a noção de cinema enquanto arte que até hoje seus documentários causam desconforto pela enorme carga psicológica que contêm. Isso não exclui o fato de todos eles serem profundamente ideológico, entretanto.

Seja para dialogar, seja para discursar, não há dúvidas que o cinema carrega consigo elementos capazes de trazer forte apelo emocional para aquele que se permite à entrega completa dentro das salas escuras ou mesmo à televisão, dentro de suas próprias casas. Assim, enquanto arte ou enquanto discurso, o cinema e os filmes por ele produzidos são dotados de linguagem, que se comunicam através de um sofisticado jogo de câmeras, luz e som, e que conversam com o espectador a um nível subconsciente, levando-o muitas vezes a acreditar naquilo que ali está exposto.

Essa ambiguidade de relação entre o real objetivo e sua imagem fílmica é uma das características fundamentais da expressão cinematográfica e determina em grande parte a relação entre do espectador com o filme, relação que vai da crença ingênua na realidade do real representado à percepção intuitiva ou intelectual dos signos implícitos como elementos de uma linguagem (MARTIN, 2007, p.18).

Pensar a relação entre o cinema e suas duas características principais significa pensar também sua relação com o capitalismo. Walter Benjamin (1985) já havia detectado nesse exato ponto a problemática que cercaria o cinema até os dias atuais, afirmando que, apenas quando esse se desvinculasse dos capitalistas é que poderia caminhar rumo ao seu papel revolucionário por natureza:

Não se deve, evidentemente, esquecer que a utilização política desse controle terá que esperar até que o cinema se liberte da sua exploração pelo capitalismo. Pois o capital cinematográfico dá um caráter contrarevolucionário às oportunidades revolucionárias imanentes a esse controle. Esse capital estimula o culto do estrelato, que não visa conservar apenas a magia da personalidade, há muito reduzida ao clarão putrefato que emana do 
seu caráter de mercadoria, mas também o seu complemento, o culto do público, e estimula, além disso, a consciência corrupta das massas, que o fascismo tenta pôr no lugar de sua consciência de classe (BENJAMIN, 1985, p. 180).

Graeme Turner (1997) afirma que o enlace entre o cinema e o capital financeiro se deu a partir do momento em que o som adentrou o universo cinematográfico. Quando a Warner Bros $^{2}$, uma das maiores empresas cinematográficas norte-americanas, se lançou nessa nova empreitada, os banqueiros da Wall Street foram convidados a investir, rompendo os muros que tornavam o cinema um núcleo fechado. A partir desse momento, os cinemas nacionais franceses, italianos, britânicos, etc., começaram a perder terreno para o cinema hollywoodiano dos norte-americanos e, como bem demonstra Marcel Martin (2007) no excerto acima, os "homens" de dinheiro, leia-se os capitalistas da indústria cinematográfica, passaram a falar em nome do gosto popular, supondo conhecer aquilo que era do interesse geral. Martin (2007) já definiu que:

Mais que seu caráter industrial, é o comercial que constitui uma grande desvantagem para o cinema, porque a importância dos investimentos financeiros que necessita o faz tributário dos poderosos, cuja única norma de ação é a rentabilidade; estes acreditam poder falar em nome do gosto do público em função de uma suposta lei de oferta e procura, cujo jogo é falseado porque a oferta modela a procura a seu bel-prazer (MARTIN, 2007, p.18).

De certa forma, o cinema enquanto ferramenta do capital consegue trazer em seu encalce um público grande de pessoas que o enxergam apenas enquanto entretenimento. Se existe algum perigo no discurso cinematográfico, certamente ele reside aí. Como já observado, longe de ser meramente uma forma de entretenimento, os filmes contêm elementos que devem ser criticamente analisados, posto que atuam em um nível sutil em nosso inconsciente. Como já definiu Jean Claude Carrière (1994), a memória das imagens é muito superior à memória das palavras, o que permite a lembrança de uma cena muito tempo depois de suas falas já terem sido completamente apagadas.

Assim, ainda que um filme pareça completamente inofensivo - como é o caso das comédias hollywoodianas, por exemplo - em suas entrelinhas contém um forte discurso normativo, que agrega visões de mundo e estilos de vida que são consumidos pelos expectadores.

Ao avaliar justamente esse consumo, Grant McCracken (2003) nos mostra a linha tênue que separa o diálogo da persuasão, que instiga o expectador - de forma inconsciente - à adotar o estilo de vida ali proposto, usar as mesmas marcas e comer as mesmas coisas. Esse

\footnotetext{
${ }^{2}$ Produtora norte-americana de filmes, programas de televisão e música.
} 
"culto de personalidades", onde o expectador projeta seus desejos para fora de sua própria vida, tende a aumentar - de acordo com o autor - já que:

Os bens do consumo são pontes para tais esperanças e ideais. São por nós utilizados para recobrar estes significados culturais deslocados, para cultivar algo que de outra maneira estaria fora de nosso alcance (MCCRACKEN, 2003, p. 135).

Assim, o cinema, enquanto constituído de imagens que agregam valor a cada cena gravada e exposta, não pode e não deve ser considerado neutro, já que perpassa economicamente uma vertente capitalista que tende a acreditar saber o que é melhor para o expectador, mascarando o discurso através da imagem.

\section{ALGUNS DADOS SOBRE O CINEMA COMERCIAL}

Ao analisarmos o papel da imagem cinematográfica, já afirmamos ser impossível encontrar um filme completamente imparcial, bem como encontrar um que possa ser taxado totalmente de mero discurso ou que possa ser considerado totalmente artístico. O contexto histórico, o lugar de criação e a visão do diretor acaba por gerar elementos que entrelaçam todos esses conceitos, fazendo do cinema a mais nova e certamente a mais problemática das artes (MARTIN, 2007).

Ainda assim, podemos elencar características que criam modelos cinematográficos específicos, que prezam certamente mais pela ideologia do que pela característica artística. Esses modelos geram filme que podem ser denominados "filmes comerciais" e são produzidos em maior quantidade, visivelmente, em território norte-americano.

Antes de analisar a produção fílmica que marcou a Guerra Fria, portanto, devemos traçar um breve panorama que mostre a evolução do cinema norte-americano pelo mundo, visualizando, assim, o caminho que o levou ao topo da indústria do entretenimento.

Já durante a Primeira Guerra Mundial, os Estados Unidos visualizaram nos mercados europeus potenciais compradores de comédias, romances e outros gêneros que fizessem as pessoas encararem a realidade da guerra de forma mais amena. A francesa Pathé Frères, até então a maior produtora de cinema comercial do mundo, começou a perder espaço para Hollywood logo a partir do início da guerra, quando sua produção passou a ser ameaçada pelo conflito físico em suas fronteiras (desvantagem territorial que os estadunidenses jamais tiveram de enfrentar):

Com o início da guerra, as indústrias cinematográficas da França e da Itália reduziram drasticamente sua produção, o mesmo acontecendo com as indústrias menos importantes da Grã-Bretanha e Alemanha. Os Estados 
Unidos entraram em mercados até então dominados por outros fornecedores [...] os resultados foram surpreendentes. [...] Até o final da guerra, os Estados Unidos estavam produzindo, segundo se dizia, $85 \%$ dos filmes de todo o mundo e 98\% daqueles exibidos na América (TURNER, 1997, p. 2324).

Entre o breve momento de paz que marcou o final da Primeira Guerra e o início da Segunda Guerra, Hollywood seguiu fortalecendo seu mercado interno com o dinheiro ganho no mercado externo. A crise de 1929 chegou a ameaçar os resultados positivos, momento em que os cinemas nacionais conseguiram ensaiar uma alavancada nas vendas. Entretanto, a ascensão dos regimes totalitários europeus logo iria enfraquecer novamente essa tentativa, abrindo caminho outra vez para a prosperidade cinematográfica hollywoodiana (TURNER, 1997).

Como já abordado, o cinema norte-americano utilizou das duas guerras para fortalecer a exportação de seus filmes comerciais, que reproduziam uma realidade romantizada muito diferente da que se encontrava fora das salas de projeção. Assim, quando os Estados Unidos adentraram a guerra em 1945 e logo colocaram um fim a ela, o que ficava claro é que se tratava da consolidação de uma potência mundial em termos fílmicos, políticos, econômicos e bélicos.

Devemos nos atentar aqui também para o fato de que a televisão se desenvolveu justamente nesse contexto, evoluindo com mais força a partir da década de 1950. Uniu-se, dessa forma, aos demais meios de comunicação para espalhar notícias e difundir imagens que o mundo passaria a absorver e consumir. Quando essa começa a tirar os espectadores das salas de cinema e a concentrá-los nas salas das casas, a indústria cinematográfica norteamericana começa a sofrer forte impacto, procurando imediatamente tomar medidas que levassem o público de volta às grandes salas escuras (TURNER, 1997).

Na maioria dos países capitalistas, as cifras que indicam o comparecimento do público aos cinemas atingiram o máximo em 1946, e a tendência geral desde então tem sido a queda. Por volta de 1953, quando quase metade de todos os lares norte-americanos tinham um aparelho de televisão, esse nível baixara à metade os números de 1946. [...] A reação da indústria cinematográfica ocorreu principalmente de duas maneiras, sendo que a tentativa de "colonizar" a televisão produzindo filmes para ela tem sido a mais bem-sucedida (TURNER, 1997, p. 27).

Longe de procurarmos perscrutar aqui as tensas relações desenvolvidas entre cinema e televisão, apontamos esse dado para que fique explicito que - com a "colonização" da televisão pelos norte-americanos - mais uma vertente de ataque direto ao inconsciente coletivo se estruturava, abrindo, assim, novas portas para a difusão da imagem heroica norteamericana e a vilanização dos inimigos através de filmes de baixo orçamento, tipicamente 
comerciais, feitos especialmente para serem assistidos no conforto doméstico após o dia de trabalho, onde pouca criticidade era exigida.

Para que entendamos a rápida difusão do cinema norte-americano pelo mundo, é preciso lembrar então o traçado que o mesmo seguiu desde a Primeira Guerra Mundial, onde Hollywood começou a ganhar terreno sobre os demais cinemas nacionais, posto que, além do cinema falado que trazia grandes novidades ao público, a devastação causada na Europa exigia uma anestesia imediata. As comédias românticas e os dramas vivenciados nas grandes telas traziam assim uma grande onda de calmaria para as pessoas comuns, que por uma ou duas horas se desligavam de uma realidade destruída e destrutiva (TURNER, 1997).

Nem mesmo a taxação de impostos baixada pelos países europeus, onde estabeleceuse cotas para produção nacional e entrada de filmes norte-americanos, freou a rápida colonização hollywoodiana (TURNER, 1997). Estima-se que em 1938 os estúdios hollywoodianos já haviam rodado cerca de 448 filmes, contra meras 41 produções daquela que viria a ser sua grande rival ao fim da Grande Guerra, a União Soviética (PROKOP, 1982, p.38).

Após o final do conflito, portanto, os Estados Unidos se erguia como um dos grandes vencedores, reforçando sua auto visão de país heroico e pacificador do mundo, além de contar com uma forte indústria cinematográfica que seria vital no conflito que se seguiria.

\section{A GUERRA FRIA PELO FILTRO DA IMAGEM}

Em meados de 1945 o mundo observava em silêncio o final da Segunda Guerra Mundial, que terminava de modo impressionante nas mãos norte-americanas sobre as cidades japonesas de Hiroshima e Nagasaki. Após cerca de seis anos de medo, onde ficou clara a capacidade humana de levar seus ideais a extremos, o cenário mundial preparava-se agora para as consequências dessa guerra.

$\mathrm{Na}$ falta de um inimigo comum, os gigantes soviéticos e estadunidenses se dividiam em duas frentes principais, rompendo a aliança que derrubou o governo nazista e lançando-se em um embate interno, que usou da propaganda e da demonstração de força para eleger um novo vencedor.

Com o fim da II Grande Guerra, emergiam do teatro de batalhas duas grandes potências bélicas: os Estados Unidos da América (EUA), cuja economia fundava-se no capitalismo e a União das Repúblicas Socialistas Soviéticas (URSS), um Estado formado por diversas repúblicas reunidas pela força centralizadora do stalinismo, cuja base econômica socialista foi 
imposta pela a Revolução bolchevique de 1917, que derrubou o último dos imperadores czaristas, da família Romanov (MORE, 1997, p. 1).

No embate entre duas ideologias políticas, sociais e econômicas, capitalismo e socialismo se viam em meio a um jogo estratégico que ficou prontamente afirmado pela ameaça nuclear. Os meios de comunicação criavam e difundiam um clima de temor frente à possibilidade de a qualquer momento o mundo extinguir-se diante das armas nucleares, cujo poder de destruição havia sido recentemente demonstrado no Japão.

Nesse sentido, iniciou-se um processo que lentamente levaria o mundo a uma polarização, ambos os lados utilizando de diversas armas para defender-se. O cinema se tornou prontamente uma das ferramentas usadas, principalmente por norte-americanos, para demonstrar os perigos de um governo regido por ideais políticos tão diferentes. Dentro das películas, o contexto histórico vivido no momento implicou na construção de estereótipos, ideologias e visões de mundo que refletiram justamente a dicotomia mundial (SOUSA, 2002, p.12).

Dentro desse contexto histórico, observamos o que foi chamado de "cinemapropaganda" ganhar cada vez mais espaço. Hollywood utilizou largamente do uso de filmes como manobra para espalhar no ocidente uma visão comum que caracterizava o bom, o honrado, o bravo e o belo como características tipicamente estadunidenses e que deveriam refletir o ocidente como um todo. Os soviéticos, por sua vez, ficaram conhecidos como os vilões feios e maus, que ameaçavam a paz no mundo e eram representados por personagens estereotipados que desvalorizavam o espirito empreendedor e capitalista dos norteamericanos. Ao longo da segunda metade do século XX, encontramos inúmeras superproduções lançadas com o intuito de tornar a União Soviética uma vilã.

As concepções ideológicas dos filmes sobre a Guerra Fria se cristalizam na defesa do anticomunismo. Mas, ao mesmo tempo, é preciso afirmar uma concepção de mundo, que será construída com base no modo de vida capitalista e no reconhecimento de virtudes no comunismo. $O$ anticomunismo, portanto, vai se amparar numa visão de mundo híbrida, construindo um imaginário que abriga diferentes concepções filosóficas e ideológicas (SOUSA, 2002, p.15).

Notemos bem que o caráter propagandístico do cinema não surge na Guerra Fria. Já na Primeira Guerra Mundial - quando o cinema ainda dava os primeiros passos - é possível encontrar alguns elementos que davam a ele poder, tanto de convencimento quanto de comoção. Entretanto, com relação à guerra, os filmes produzidos no contexto bélico tendiam a exibir mais mensagens de paz do que necessariamente fazer apologia a este ou aquele lado (ESPANA, 1996, p.1), fato que mudou radicalmente na Segunda Guerra Mundial. 
Os soviéticos e os nazistas foram os primeiros a encarar o cinema em toda sua amplitude, analisando sua função, atribuindo-lhe um estatuto privilegiado no mundo do saber, da propaganda, da cultura. (...) O cinema não foi apenas um instrumento de propaganda para os nazistas. Ele também foi, por vezes, um meio de informação, dotando os nazistas de uma cultura paralela. (...) Os nazistas foram os únicos dirigentes do século XX cujo imaginário mergulhava, essencialmente, no mundo da imagem (FERRO, 1992, p. 72-73).

O apelo propagandístico através da imagem, que foi usada pelos países e seus dirigentes nas mais diversas formas, causou grande impacto no consciente e inconsciente coletivo. Através delas as pessoas desenvolveram um forte senso de pertencimento à nação e noção da existência de um inimigo, já que a visualidade imagética dava um corpo muito mais concreto à realidade do que o discurso e as palavras. Escrevendo em 1926, Siegfried Kracauer já identificava o reconhecimento das pessoas no espelho imagético, nesse caso, cinematográfico. Benjamin (1985), mais tarde, iria escrever justamente sobre a identificação das massas com a representação da realidade ali exposta:

Porque é diante de um aparelho que a esmagadora maioria dos citadinos precisa alienar-se de sua humanidade, nos balcões e nas fábricas, durante o dia de trabalho. À noite, as mesmas massas enchem os cinemas para assistirem à vingança que o intérprete executa em nome delas, na medida em que o ator não somente afirma diante do aparelho sua humanidade (ou o que aparece como tal aos olhos dos espectadores), como coloca esse aparelho a serviço do seu próprio triunfo (BENJAMIN, 1985, p. 179).

No caso do cinema norte-americano, o período que concentrou a Segunda Guerra Mundial gerou um enorme sentimento nacionalista, sentimento esse que floresceria amplamente durante a Guerra Fria. Filmes como Tempestade Mortal (1940) ${ }^{3}$ e As Confissões de um Espião Nazista (1939) ${ }^{4}$, dotados de elementos tipicamente hollywoodianos, são exemplos da postura estadunidense adotada perante o conflito.

Dentro do cinema norte-americano, portanto, podemos notar algumas estratégias fundamentais utilizadas por cineastas (muitas vezes a mando de seus governantes) com caráter claramente propagandísticos: o destaque constante dos Estados Unidos e o heroísmo de seus soldados, as dificuldades que são paulatinamente superadas, a superioridade bélica e a inevitável vitória dos norte-americanos sobre seus inimigos (LOBASSI, 2008). A Guerra Fria apenas ajudaria a alavancar o consumo desses elementos, consolidando uma imagem que já vinha deixando sua marca.

\footnotetext{
${ }^{3}$ Com o título original de Mortal Storm, o filme retrata os efeitos da ascensão de Hitler ao poder em uma pequena cidade alemã e, mais especificamente, na vida de uma determinada família contrária ao nazismo.

${ }^{4} \mathrm{O}$ filme, com o título original de Confessions os a nazy spy, retrata a investigação de um agente americano sobre uma possível rede de espionagem nazista nos Estados Unidos.
} 
Mesmo não sendo considerada propriamente um conflito, a Guerra Fria manteve o mundo em tensão desde o final da Segunda Guerra. Enquanto os conflitos internacionais anteriores guardavam certa relação, ainda que distante, com o século XIX, o embate entre Estados Unidos e União Soviética deslocou a disputa para um âmbito teórico totalmente novo, que colocava frente a frente dois sistemas econômicos. A guerra deixava de ser territorial e passava a ser psicológica.

Essa nova característica relacionou-se perfeitamente bem com os meios de comunicação que vigoravam de forma intensa após o fatídico ano de 1945. Divulgando em tempo quase real os acontecimentos, o rádio e a televisão mantinham seu papel de ponte entre o político e o social, enquanto o cinema supria o âmbito cultural. Inaugurada a era nuclear que forçou uma corrida armamentista, espacial e política, a Guerra Fria criava novos cenários mundiais, que dia após dia trazia e incorporava novas mudanças.

A situação delicada era marcada fortemente pelo cenário político, onde (em meados de 1950) o senador estadunidense Joseph Raymond McCarthy ganhava popularidade cada vez maior ao propagar ideais anticomunistas, transformando o pequeno e quase inexpressivo Partido Comunista norte-americano em um grupo extremamente impopular e perigoso, que ameaçava diretamente o american way of life, ou "estilo de vida americano".

McCarthy, em seu movimento de "perseguição" aos considerados simpatizantes comunistas, foi responsável pela criação de uma espécie de lista negra. Nesta foram incluídos nomes de artistas, intelectuais, membros de sindicatos, entre outros, que foram convidados a prestar depoimentos públicos na chamada Comissão de Assuntos Antiamericanos e mesmo a deixar o país (inclusive Chaplin, que deixaria os Estados Unidos após a repercussão de Mounsieur Verdoux (1947), no qual fazia críticas ao militarismo e ao capitalismo em uma áurea de humor negro).

Ainda que após 1954 os meios utilizados por McCarthy passassem a ser condenados, a postura anticomunista americana não afrouxou, buscando apenas outros métodos de ação diferentes da "caça as bruxas" anteriormente operada.

Com a década de 1960, o Departamento de Defesa dos Estados Unidos iniciou uma parceria com diretores e cineastas, financiando filmes que elevassem a imagem vitoriosa dos norte-americanos. O Mais Longo dos Dias (1962) é um exemplo bem sucedido dessa parceria, que faz um retrato bastante parcial do chamado Dia D, momento marcante do fim do regime nazista. Uma Batalha no Inferno ${ }^{5}$ (1965) e Tora! Tora! Tora! ${ }^{6}$ (1970), também são exemplos

\footnotetext{
${ }^{5}$ Do original Batlle Of Bulge, o filme retrata uma reação nazista aos fins da Segunda Guerra Mundial.
} 
de uma filmografia patrocinada pelo Governo norte-americano, que visava passar a imagem de uma nação superior. Rambo - First Blood (1982) e as sequencias de 007 que iniciaram-se em 1953 também são clássicos momentos em que o herói ocidental luta e supera o inimigo soviético. Nesse sentido, como afirma Kracauer:

Os filmes de uma nação refletem a mentalidade desta de uma maneira mais direta do que qualquer outro meio artístico (...). Primeiro, os filmes nunca são produto de um indivíduo (...) segundo porque os filmes são destinados às multidões anônimas. (...) Ao gravar o mundo visível - não importa se a realidade vigente com um universo imaginário - os filmes proporcionam a chave de processos mentais ocultos. (...) O que conta não é tanto a popularidade dos filmes estatisticamente mensurável, mas a popularidade de seus temas pictóricos e narrativos (KRACAUER, 1988, p.17).

Se o conflito por si só foi amplamente trabalhado pelos Estados Unidos em suas películas, o final vitorioso curiosamente não despertou uma grande onda produtora de filmes. Após quase cinquenta anos de uma disputa mental exaustiva, com picos altos e baixos de tensão e onde os países quase chegaram as vias de fato, em 1989 o muro de Berlim vinha abaixo, representando o fim da bipolaridade mundial, final que foi mais retratado pela Europa do que pelos estadunidenses.

\section{CONSIDERAÇÕES}

Ao traçarmos essas breves considerações sobre o cinema e sobre a cinematografia durante a Guerra Fria, bem como o papel das imagens nesse conflito, buscamos demonstrar a força de ação que essa ferramenta tem enquanto artefato visual. Paul Valery definiu com presteza tal capacidade ao afirmar que:

Sobre a tela estendida, sobre o plano sempre puro onde nem a vida nem o próprio sangue jamais deixam traços, os acontecimentos mais complexos se reproduzem quantas vezes se quiser. As ações são aceleradas ou retardadas. A ordem dos fatos é reversível. Os mortos revivem e riem (...). Vemos a precisão do real revestir todos os atributos do sonho. É um sonho artificial. É também uma memória exterior, e dotado de uma perfeição mecânica. Enfim, graças às imobilizações e aos aumentos, a própria atenção se fixa. Minha alma divide-se por tais encantamentos. Ela se projeta na tela onipotente e movimentada; participa das paixões dos fantasmas que ali se produzem (VALERY apud MARTIN, 2007, p. 20).

Concluímos, ao final desse trabalho, que o cinema é sem dúvida uma arte problemática, que foi sendo refinada ao longo do tempo e, nas mãos de produtores, passou a reproduzir ilusões que começaram a ser vendidas como verdade. Esse processo gerou não

\footnotetext{
${ }^{6}$ Filme particionado entre estadunidenses e japoneses, mostra em caráter quase documental tanto o lado japonês quanto norte-americano no ataque à Pearl Harbor.
} 
apenas propagandas e ideologias, mas também ajudou a criar um culto ao estrelato que se perpetua até hoje, gerando uma onda de consumo que se estende até a televisão e nela se multiplica de formas infinitas. Deve-se lembrar constantemente, ao questionarmos o cinema e suas potencialidades, que o mesmo não é neutro. Que jamais o será.

Nesse viés, urge repensar o papel do cinema na cultura e na sociedade não mais como mero reprodutor da realidade ou tendo como função o simples entretenimento, mas enquanto uma ferramenta capaz de conversar e também de impor, capacidades essas que devem ser criticamente e permanentemente avaliadas. Como bem definiu Marcel Martin (2007), a imagem não é começo, mas resultado. Resultado de uma sociedade que a produz, que ali expõe suas particularidades, suas visões de mundo, seus estereótipos e singularidades, que se verifica como reflexo ou como reinvenção da realidade, e, se a ambos nos cabe questionar, é instigante como método e como perspectiva.

\section{REFERÊNCIAS}

ALVES, Joice Prado; ALVES, Renan Prado. Considerações acerca da cinematografia sob a ótica de Walter Benjamin. Orson - Revista dos Cursos de Cinema do Cearte UFPEL, v. 2, p. 247-259, 2012.

CARRIÈRE, Jean Claude. A Linguagem Secreta do Cinema. Rio de Janeiro: Nova Fronteira, 2006.

PROKOP, Dieter. A Estrutura Monopolista Internacional da Produção Cinematográfica. São Paulo, Ática, 1982.

ESPAÑA, Rafael de. Guerra, Cinema e Propaganda. Revista Olho da História. Salvador: n. 3, Universidade Federal da Bahia, 1996. Disponível em: <

http://www.oolhodahistoria.ufba.br/o3rafael.html>

FERRO, Marc. O filme: uma contra-análise da sociedade? In: LE GOFF, Jacques; NORA, Pierre (Orgs.) História: novos objetos. Rio de Janeiro: Paz e Terra, 1992, p. 79-115.

JOURNOT, Marie-Thérèse. Vocabulário de cinema. Lisboa: Edições 70, 2005.

KRACAUER, S. De Caligari a Hitler: uma história psicológica do cinema alemão. Rio de Janeiro: Jorge Zahar, 1988.

KELLNER, Douglas. A cultura da mídia. Bauru: Edusc, 2001.

LOBASSI, Edmundo Washington. A ideologia nos Filmes de Guerra - o Cinema como meio. Revista Universitária do Audiovisual. Ano 1, Número 02, jul/2008. Universidade Federal de São Carlos, 2008. Disponível em: < http://www.rua.ufscar.br/site/?p=3> 
MARTIN, Marcel. A linguagem cinematográfica. São Paulo: Brasiliense, 2007.

MORE, Rodrigo Fernandes. A Guerra Fria: 1945 - 1987. Estudo baseado na obra de Eric

HOBSBAWM, A Era dos Extremos - O breve século XX - 1914-1991, São Paulo,

Companhia das Letras, $2^{a}$ ed., 1997, p. 223/252.

SOUSA, Antonio Cícero Cassiano. Cinema e Política: O Anticomunismo nos filmes sobre a Guerra Fria (1948-1969). Tese de Doutorado - Universidade Federal Fluminense. 2002.

Disponível em < http://pt.scribd.com/doc/14667396/Cinema-no-Contexto-da-Guerra-Fria->

TURNER, Graeme. Cinema como prática social. São Paulo: Summus, 1997.

\section{REFERÊNCIAS AUDIOVISUAIS}

MORTAL, Tempestade. Direção: Frank Borzage. Warner Bros, 1940 (100 min).

NAZISTA, Confissões de um espião. Direção: Anatole Litvak. Warner Bros, 1939 (104 min).

VERDOUX, Monsieur. Direção: Charles Chaplin. 1947 (124 min).

DIAS, O mais longo dos. Direção: Ken Annakin, Andrew Marton, Bernhard Wicki, Gerd Oswald, Darryl F. Zanuck. 20 Fox, 1962. (180 min)

TORA! Tora! Tora! Direção: Kinji Fukasaku, Toshio Masuda, Richard Fleischer. 20 Fox, 1970. (144 min)

INFERNO, Uma batalha no. Direção: Ken Annakin. Warner Bros, 1965 (167 min)

RAMBO. Direção: Ted Kotcheff. 1982 (97 min).

Original recebido em: 08/03/2013

Aceito para publicação em: 05/08/2015

Denise Marcos Bussoletti

Doutorado em Psicologia pela Pontifícia Universidade Católica do Rio Grande do Sul (2007), com estágio no Instituto de Estudos da Criança (IEC) da Universidade do Minho, Braga Portugal. Mestrado em Psicologia pela Pontifícia Universidade Católica do Rio Grande do Sul (1997) e Graduação em Psicologia pela Universidade Católica de Pelotas (1987). Atualmente é professora da Universidade Federal de Pelotas. Tem experiência na área de Educação e Psicologia, com ênfase em Psicologia Social.

Joice do Prado Alves

Mestrado em Educação pela Universidade Federal de Pelotas (2014), Graduação em História pela Universidade Estadual Paulista (campus - Franca) (2011), Graduação em andamento no curso de Pedagogia pela Universidade Federal do Rio de Janeiro (2015). Possui ênfase de 
pesquisa em torno dos estudos da infância e dos aparatos audiovisuais dentro do campo educacional. 